\title{
MANEJO DA ADUBAÇÃO FOSFATADA E POTÁSSICA NO CULTIVO SUCESSIVO DE MILHO E SORGO PARA SILAGEM
}

\author{
CLOVIS ORLANDO DA ROS ${ }^{1}$, JÚNIOR MELO DAMIAN ${ }^{2}$, MARCIA MATSUOKA ${ }^{1}$, \\ GUTIÉRRI LOURENÇO CAMPOS ${ }^{1}$, FELIPE BONINI DA LUZ ${ }^{1}$, ANA JULIA OLIBONE ${ }^{1}$ \\ e LUCINDO SOMAVILLA ${ }^{1}$
}

${ }^{1}$ Universidade Federal de Santa Maria, Campus de Frederico Westphalen,

CEP: 98400-000, Caixa Postal 54, Frederico Westphalen, RS.E-mail: clovisdaros@gmail.com,marciamatsuoka@yahoo.com.br, boninisolos@gmail.com,gutierri_lorenco33@hotmail.com,ana.julia.olibone@gmail.com,lucindosomavilla@hotmail.com ${ }^{2}$ Universidade de São Paulo, ESALQ, CEP 13418-900, Caixa Postal 9, Piracicaba, SP. E-mail: juniormelodamian@hotmail.com

Revista Brasileira de Milho e Sorgo, v.18, n.1, p. 14-29, 2019

RESUMO - O manejo da adubação nas culturas de sorgo e milho para a silagem com base na quantidade exportada de nutrientes é uma alternativa para manter a produtividade de biomassa em áreas com teores "muito altos" dos elementos no solo. Diante disso, o trabalho teve por objetivo quantificar a reposição de P e K e a variação dos nutrientes no solo em área de cultivo sucessivo de milho e sorgo para silagem. Foram implantados dois experimentos com cinco cultivos sucessivos entre os anos de 2013 e 2016 (três cultivos de milho e dois de sorgo). O delineamento foi de blocos casualizados, com quatro repetições. Os tratamentos foram doses de $0,40,80,120$ e $160 \mathrm{~kg} \mathrm{ha}^{-1} \mathrm{de}_{2} \mathrm{O}_{5}$ no experimento I, e $0,30,60,90$ e $120 \mathrm{~kg} \mathrm{ha}^{-1}$ de $\mathrm{K}_{2} \mathrm{O}$ no experimento II, aplicadas em cada cultivo. O balanço de nutrientes no sistema de cultivo de milho e sorgo indicou $95,3 \mathrm{~kg} \mathrm{ha}^{-1}$ de $_{2} \mathrm{O}_{5}$ e $297,3 \mathrm{~kg} \mathrm{ha}^{-1}$ de $\mathrm{K}_{2} \mathrm{O}$ para contrabalançar as exportações dos nutrientes, equivalendo à reposição de $5,2 \mathrm{~kg} \mathrm{de} \mathrm{P}_{2} \mathrm{O}_{5}$ e $15,7 \mathrm{~kg}$ de $\mathrm{K}_{2} \mathrm{O}$ por megagrama de matéria seca produzida. $\mathrm{O}$ uso das doses de reposição durante cinco cultivos sucessivos das forrageiras manteve a disponibilidade de $\mathrm{P}$ próximo e de $\mathrm{K}$ acima dos teores originais na camada de $0-20 \mathrm{~cm}$.

Palavras-chave: Zea mays L., Sorghum bicolor L., forragem, exportação de nutrientes.

\section{MANAGEMENT OF PHOSPHATE AND POTASSIUM FERTILIZATION IN THE SUCCESSIVE CULTIVATION OF CORN AND SORGHUM FOR SILAGE}

\begin{abstract}
Fertilization management in sorghum and corn crops for silage based on the exported amount of nutrients is an alternative to maintain the productivity of biomass in areas with "very high" levels of the elements in the soil. Therefore, the objective of this work was to quantify the replacement of $\mathrm{P}$ and $\mathrm{K}$ and the nutrient variation in the soil in a successive corn and sorghum silage area. Two experiments were carried out with five successive crops from 2013 to 2016 (three maize and two sorghum crops). The experiment used a randomized complete block design with four replications. The treatments were $0,40,80,120$ and $160 \mathrm{~kg} \mathrm{ha}^{-1}$ of $\mathrm{P}_{2} \mathrm{O}_{5}$ in the experiment I and 0, 30, 60, 90 and $120 \mathrm{~kg} \mathrm{ha}^{-1} \mathrm{~K}_{2} \mathrm{O}$ in the experiment II, applied to each crop. The nutrient balance in the maize and sorghum succession system indicated $95.3 \mathrm{~kg} \mathrm{ha}^{-1}$ of $\mathrm{P}_{2} \mathrm{O}_{5}$ and $297.3 \mathrm{~kg} \mathrm{ha}^{-1}$ of $\mathrm{K}_{2} \mathrm{O}$ to compensate the exports of nutrients, corresponding to the need to replace $5.2 \mathrm{~kg}$ of $\mathrm{P}_{2} \mathrm{O}_{5}$ and $15.7 \mathrm{~kg}$ of $\mathrm{K}_{2} \mathrm{O}$ per megagram of dry matter produced. The use of replenishment rates during five successive fodder crops maintained the availability of $\mathrm{P}$ near and $\mathrm{K}$ above the original contents in the $0-20 \mathrm{~cm}$ layer.
\end{abstract}

Keywords: Zea mays L., Sorghum bicolor L., Moench., forage, nutrient export. 
A maior resposta das culturas à aplicação de fósforo (P) e de potássio (K) ocorre quando os teores dos nutrientes no solo estão abaixo do nível crítico para o desenvolvimento das plantas. A partir deste valor, existem duas faixas de disponibilidade do nutriente no solo: uma considerada adequada, definida como teor "alto", e a outra acima da faixa adequada (teor "muito alto"), que são interpretadas com base na metodologia de determinação do elemento no solo e com estudos de correlação de resposta das plantas à aplicação do nutriente no solo (Schlindwein \& Gianello, 2008; Kaminski et al., 2010).

A recomendação de adubação da Comissão de Química e Fertilidade do Solo da Sociedade Brasileira de Ciência do Solo para os Estados de Santa Catarina e Rio Grande do Sul, região Sul do Brasil (Manual, 2016), especifica que os teores de P e K disponíveis no solo devem estar dentro da faixa adequada de interpretação dos nutrientes, adicionando uma quantidade maior de adubação para a correção do teor do nutriente, quando está abaixo do nível crítico, uma quantidade para manter os teores no solo quando está dentro da faixa adequada (teor "alto") e uma quantidade menor, definida como adubação de reposição, quando os teores se encontram acima da faixa adequada (teor "muito alto").

A recomendação de adubação para as culturas de milho e de sorgo para silagem em solo com P e K acima da faixa adequada é com base no valor de manutenção, que é a soma da quantidade exportada mais a perda do nutriente no solo, diferente das culturas destinadas à produção de grãos, que têm a opção de usar somente a adubação com base na taxa de exportação (Manual, 2016).

Como a perda de $\mathrm{P}$ e K no solo é variável entre os tipos de solo, declividade do terreno e práticas de manejo e conservação, somados ao rendimento de massa seca e à concentração dos nutrientes, que são parâmetros utilizados para o cálculo da exportação pelas plantas forrageiras, que também são variáveis entre os híbridos e as condições edafoclimáticas de cada local (Von Pinho et al., 2009; Skonieski et al., 2010; Oliveira et al., 2010; Rabêlo et al., 2013; Ueno et al., 2013; Santos et al., 2015), muitas vezes há dificuldade de decisão do técnico em definir a dose da adubação com o objetivo de repor somente o que a cultura exporta.

Em áreas de cultivos sucessivos de forrageiras para silagem em comparação ao cultivo de grãos, a redução da disponibilidade de $\mathrm{P}$ e $\mathrm{K}$ no solo é mais acentuada por causa da alta taxa de exportação dos nutrientes, podendo diminuir gradativamente a produtividade (Silva et al., 2010; Ueno et al. 2013). As áreas de produção de silagem exportam $74 \%$ de $\mathrm{P}$ e $384 \%$ de $\mathrm{K}$ a mais em comparação à exportação somente pelos grãos (Ueno et al., 2013). O P é o terceiro e o $\mathrm{K}$ pode ser o segundo ou o primeiro na ordem de acumulação de nutrientes na biomassa do milho e sorgo para silagem (Von Pinho et al., 2009; Oliveira et al., 2010; Ueno et al., 2013; Santos et al., 2015). Assim, a adequação de doses equivalentes à taxa de exportação é a forma de manter os teores dos nutrientes no solo dentro da faixa adequada.

Neste contexto, o objetivo do trabalho foi quantificar a dose de reposição de P e K em solo com teor "muito alto" e a variação da disponibilidade dos nutrientes em cultivos sucessivos de milho e sorgo para silagem.

\section{Material e Métodos}

O estudo foi conduzido durante três anos, com três cultivos de milho (Zea mays L.) na safra de verão e dois de sorgo na safrinha (Sorghum bicolor L. 
Moench), na área experimental da Universidade Federal de Santa Maria, campus de Frederico Westphalen, RS, localizado na latitude $27^{\circ} 23^{\prime} 23,75^{\prime \prime}$ Sul, longitude $53^{\circ} 25^{\prime} 41,18^{\prime \prime}$ Oeste e altitude de $484 \mathrm{~m}$. O clima da região é subtropical úmido com verão quente, tipo Cfa, com máximas iguais ou superiores a $22{ }^{\circ} \mathrm{C}$, mínimas entre -3 e $18{ }^{\circ} \mathrm{C}$ e precipitação média anual entre 1.900 e $2.200 \mathrm{~mm}$ (Alvares et al., 2013). As precipitações e as temperaturas médias das máximas e mínimas no período de condução do experimento (outubro/2013 a janeiro de 2016) estão especificadas na Figura 1.

A área do experimento vinha sendo manejada sob sistema plantio direto há mais de cinco anos, com cultivos de soja [Glycine $\max (\mathrm{L}$.) Merr] e milho (Zea mays L.) nas safras de verão, e com aveia-preta (Avena strigosa Schreb) como cultura de cobertura do solo no período de inverno. O solo da área experimental foi caracterizado como Latossolo Vermelho (Santos et al., 2014). Os atributos físicos e químicos determinados antes da instalação do experimento estão especificados na Tabela 1.

Os teores de nutrientes disponíveis foram quantificados conforme metodologias de análises químicas para avaliação da fertilidade do solo, descrita em Silva et al. (2009), usando extratores Mehlich-1 para $\mathrm{P}$ e K, solução $\mathrm{KCl} 1 \mathrm{~mol} \mathrm{~L}^{-1}$ para extração $\mathrm{Ca}$ e $\mathrm{Mg}$ e solução $\mathrm{HCl}$ 0,1 mol L-1 para $\mathrm{Cu}$ e Zn. A acidez trocável foi extraída com solução $\mathrm{KCl} 1 \mathrm{~mol} \mathrm{~L}^{-1}$ e a acidez potencial foi estimada pelo índice SMP. Os atributos físicos foram quantificados pela metodologia da Embrapa (Donagema et al., 2011).

O delineamento experimental utilizado foi o de blocos ao acaso, com quatro repetições, em parcelas de $4 \times 3 \mathrm{~m}$, totalizando uma área de $12 \mathrm{~m}^{2}$ por parcela. Os tratamentos foram compostos de cinco doses distintas de fósforo $(\mathrm{P})$ e potássio $(\mathrm{K})$, aplicadas nas culturas de milho e sorgo, sendo que cada nutriente caracterizou um experimento. As doses foram de 0 , $40,80,120$ e $160 \mathrm{~kg} \mathrm{ha}^{-1}$ de $\mathrm{P}_{2} \mathrm{O}_{5}$ no experimento I,

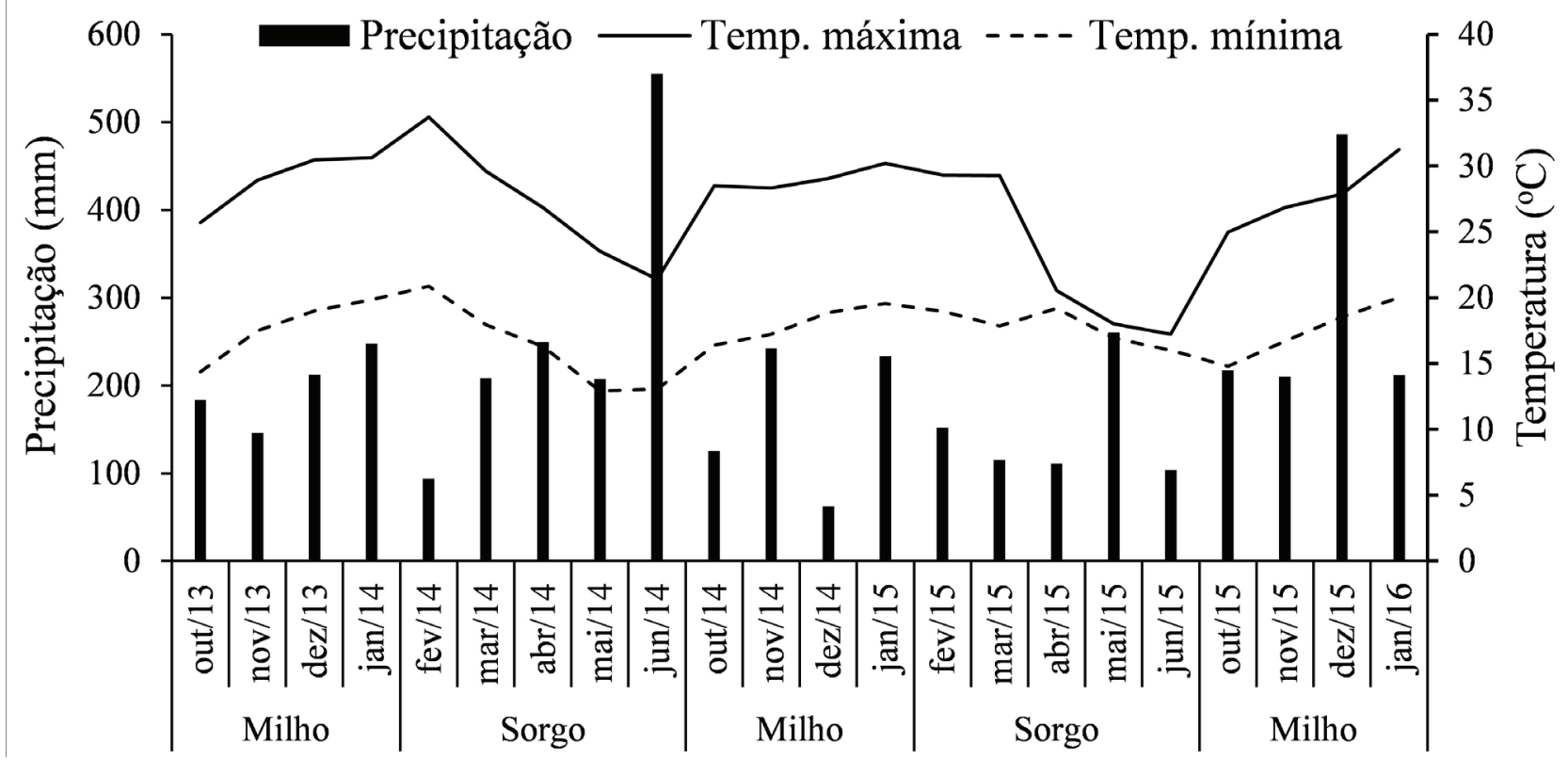

Figura 1. Precipitação, temperatura média da máxima e da mínima mensal durante o período de condução do experimento com as culturas de milho e sorgo. 
Tabela 1. Atributos químicos e físicos em diferentes camadas do solo da área experimental na implantação do experimento

\begin{tabular}{|c|c|c|c|c|c|c|c|}
\hline \multirow{2}{*}{ Camada $(\mathrm{cm})$} & $\mathrm{Al}$ & $\mathrm{Ca}$ & $\mathrm{Mg}$ & $\mathrm{P}$ & $\mathrm{K}$ & $\mathrm{Cu}$ & $\mathrm{Zn}$ \\
\hline & \multicolumn{3}{|c|}{--- $\mathrm{cmol}_{\mathrm{c}} \mathrm{dm}^{-3}$} & \multicolumn{4}{|c|}{ 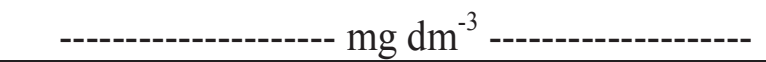 } \\
\hline $00-10$ & 0,1 & 4,7 & 2,5 & 13,4 & 309,5 & 11,2 & 3,3 \\
\hline $10-20$ & 0,1 & 4,3 & 2,4 & 5,2 & 179,5 & 12,7 & 3,2 \\
\hline $20-40$ & 0,1 & 4,0 & 2,5 & 1,5 & 93,6 & 12,8 & 1,1 \\
\hline $40-60$ & 0,5 & 2,1 & 1,4 & 1,6 & 42,3 & 9,6 & 0,6 \\
\hline $60-80$ & 0,3 & 2,2 & 1,5 & 1,3 & 28,0 & 8,3 & 0,3 \\
\hline $80-100$ & 0,2 & 2,0 & 1,4 & 1,4 & 22,1 & 8,9 & 0,4 \\
\hline $100-120$ & 0,6 & 1,2 & 0,8 & 1,1 & 29,2 & 9,6 & 0,3 \\
\hline $120-140$ & 1,3 & 0,6 & 0,4 & 1,5 & 31,0 & 9,1 & 0,3 \\
\hline $140-160$ & 1,3 & 0,5 & 0,2 & 2,5 & 21,5 & 8,3 & 0,2 \\
\hline \multirow[t]{2}{*}{$160-180$} & 1,5 & 0,4 & 0,2 & 2,3 & 29,8 & 9,2 & 0,5 \\
\hline & $\mathrm{pH}$ & $\begin{array}{c}\mathrm{MO} \\
\left(\mathrm{g} \mathrm{dm}^{-3}\right)\end{array}$ & \multicolumn{3}{|c|}{--- $\mathrm{cmol}_{\mathrm{c}} \mathrm{dm}^{-3}$} & \multicolumn{2}{|c|}{------- \% -------- } \\
\hline $00-10$ & 5,5 & 28,2 & 4,4 & 7,9 & 12,2 & 64,6 & 1,9 \\
\hline $10-20$ & 5,5 & 26,8 & 3,9 & 7,4 & 11,2 & 64,7 & 1,9 \\
\hline $20-40$ & 5,8 & 24,7 & 3,3 & 6,9 & 10,1 & 67,4 & 0,9 \\
\hline $40-60$ & 5,5 & 19,4 & 3,5 & 4,1 & 7,1 & 51,2 & 11,2 \\
\hline $60-80$ & 5,6 & 16,4 & 3,2 & 4,0 & 7,0 & 53,4 & 7,5 \\
\hline $80-100$ & 5,6 & 14,9 & 3,1 & 3,7 & 6,6 & 52,8 & 4,7 \\
\hline $100-120$ & 5,4 & 13,0 & 3,4 & 2,6 & 5,5 & 37,3 & 21,9 \\
\hline $120-140$ & 5,0 & 13,0 & 4,3 & 2,3 & 5,3 & 19,8 & 54,5 \\
\hline $140-160$ & 4,9 & 13,3 & 4,4 & 2,1 & 5,1 & 15,0 & 63,5 \\
\hline \multirow[t]{2}{*}{$160-180$} & 4,5 & 12,1 & 4,4 & 2,1 & 5,4 & 11,6 & 70,1 \\
\hline & Argila & $\begin{array}{c}\text { Silte } \\
-\mathrm{g} \mathrm{kg}^{-1} \\
\end{array}$ & Areia & $\begin{array}{c}\text { Ds } \\
\left(\mathrm{kg} \mathrm{dm}^{-3}\right)\end{array}$ & PT & $\begin{array}{l}\text { Micro } \\
\mathrm{m}^{3} \mathrm{dm}^{-3}\end{array}$ & Macro \\
\hline $00-10$ & 616,3 & 81,7 & 301,9 & 1,22 & 0,54 & 0,42 & 0,12 \\
\hline $10-20$ & 636,9 & 66,9 & 296,2 & 1,30 & 0,51 & 0,44 & 0,07 \\
\hline $20-40$ & 637,7 & 70,5 & 291,8 & 1,22 & 0,54 & 0,44 & 0,10 \\
\hline $40-60$ & 663,7 & 68,0 & 268,3 & 1,09 & 0,59 & 0,41 & 0,18 \\
\hline $60-80$ & 647,7 & 72,4 & 279,9 & 1,00 & 0,62 & 0,39 & 0,23 \\
\hline $80-100$ & 627,4 & 88,5 & 284,1 & 1,13 & 0,57 & 0,42 & 0,16 \\
\hline $100-120$ & 668,5 & 73,4 & 258,1 & 1,06 & 0,60 & 0,41 & 0,19 \\
\hline $120-140$ & 748,5 & 37,5 & 213,9 & 0,97 & 0,63 & 0,44 & 0,20 \\
\hline $140-160$ & 744,0 & 37,5 & 218,5 & 0,97 & 0,63 & 0,44 & 0,19 \\
\hline $160-180$ & 656,1 & 62,9 & 281,0 & 1,02 & 0,61 & 0,45 & 0,16 \\
\hline
\end{tabular}


e $0,30,60,90$ e $120 \mathrm{~kg} \mathrm{ha}^{-1}$ de $\mathrm{K}_{2} \mathrm{O}$ no experimento II, aplicadas a lanço e sem incorporação no solo, na forma de superfosfato triplo e cloreto de potássio, respectivamente. Nos dois experimentos foram usadas doses fixas de N: $20 \mathrm{~kg} \mathrm{ha}^{-1}$ na semeadura e $150 \mathrm{~kg}$ $\mathrm{ha}^{-1}$ em cobertura, na forma de ureia, quando as duas culturas estavam com quatro folhas expandidas. No experimento com doses de $\mathrm{P}$ foi usada uma dose fixa de $90 \mathrm{~kg} \mathrm{ha}^{-1}$ de $\mathrm{K}_{2} \mathrm{O}$ e no experimento com doses de $\mathrm{K}$ foram usados $120 \mathrm{~kg} \mathrm{ha}^{-1} \mathrm{de}_{2} \mathrm{O}_{5}$.

A cultura do milho foi semeada no mês de outubro nos três anos avaliados, com semeadora adubadora para plantio direto e no espaçamento de $0,45 \mathrm{~cm}$. Nas safras 2013/14 e 2014/15 foi utilizado o híbrido 2A120Hx da Dow AgroSciences, e na safra 2015/16, o híbrido 30A77Hx da Morgan Sementes. Foram utilizadas 3,8 plantas por metro linear, com população média final de 70.000; 75.000 e 78.000 plantas ha ${ }^{-1}$ nas safras 2013/14, 2014/15 e 2015/16, respectivamente.

O sorgo foi semeado no mês de fevereiro nos dois anos avaliados, no mesmo espaçamento e com a mesma semeadora utilizada para o milho. Em 2014 foi usado o híbrido AG 2501 da Agroceres, e em 2015, o forrageiro Sunchales NR da Wolf Seeds. Foram utilizadas em média 8,0 plantas por metro linear e população média final nas respectivas safras de 140.000 e 120.000 plantas ha ${ }^{-1}$. A cultura do sorgo foi semeada após a retirada de todas as plantas de milho da área experimental. Após o cultivo de sorgo, também foram retiradas as plantas da área experimental, simulando áreas de produção de forrageiras para silagem. No inverno, a área permaneceu em pousio sem cultivo de forrageiras.

A colheita das plantas foi realizada quando apresentou entre 32 a 35\% de massa seca, estádio recomendado para a prática de ensilagem. Coletaram- se na área útil de cada parcela oito plantas de milho e 2,0 m lineares de sorgo, entre 20 e $25 \mathrm{~cm}$ de altura do solo. As plantas coletadas da área útil foram trituradas com auxílio de um triturador forrageiro e submetidas à secagem em estufa a $65^{\circ} \mathrm{C}$, até se obter massa constante.

Os dados foram transformados e expressos em produtividade de massa seca $\left(\mathrm{kg} \mathrm{ha}^{-1}\right)$. No milho foi calculado com base no número de plantas coletadas e na população final, e, no sorgo, com base na área coletada $\left(0,90 \mathrm{~m}^{2}\right)$. Posteriormente, retiraram-se subamostras que foram moídas em moinho tipo "Willey" com peneira com malha de $1,0 \mathrm{~mm}$. No material seco e moído foi quantificada a concentração de $\mathrm{P}$ e $\mathrm{K}$, conforme metodologias para análises química para tecido vegetal, descritas em Miyazawa et al. (2009).

Com base na concentração dos nutrientes e na respectiva produtividade de massa seca foi calculada a quantidade de $\mathrm{P}$ exportada pela biomassa das forrageiras $\left(\mathrm{kg} \mathrm{ha}^{-1}\right)$. O balanço de $\mathrm{P}$ no sistema de produção de milho e sorgo para silagem foi calculado por meio da diferença entre a quantidade exportada pela biomassa da forragem e as respectivas doses do nutriente aplicadas via adubação.

Em abril de 2016, após o último cultivo de milho, foram abertas trincheiras e coletadas amostras de solo nas camadas 0-10,0 e 10,0-20,0 cm, com auxílio de pá de corte, em quatro pontos aleatórios em cada parcela. As amostras após secas em estufa a $40{ }^{\circ} \mathrm{C}$ e moídas foram submetidas à extração de $\mathrm{P}$ e $\mathrm{K}$ com a solução Mehlich-1, conforme metodologia para avaliação dos teores disponíveis no solo, descrita em Silva et al. (2009).

Os resultados foram submetidos à análise de variância para cada safra e as médias de tratamentos foram ajustadas por meio de análise de regressão polinomial a $5 \%$ de probabilidade de erro $(\mathrm{p} \leq 0,05)$, uti- 
lizando-se o programa Statistical Analysis System SAS 8.0. A dose de reposição de P foi calculada com base na equação de regressão, estimada com os dados do balanço de $\mathrm{P}$ e as respectivas doses do nutriente aplicadas em cada cultivo, definida quando o balanço de $\mathrm{P}$ é igual a zero (dose aplicada igual à quantidade exportada).

Os teores de $\mathrm{P}$ e $\mathrm{K}$ encontrados nas duas camadas e na média da camada $0-20 \mathrm{~cm}$ foram correlacionados com as respectivas quantidades aplicadas e ajustadas doses necessárias para manter os teores dos nutrientes, após cinco cultivos, no limite superior (LS) e limite inferior (LI) da faixa adequada (teor alto), conforme definido pela Comissão de Química e Fertilidade do Solo (Manual..., 2016), com valores entre 6,1 e 9,0 $\mathrm{mg} \mathrm{dm}^{-3}$ de P e entre 90 e 180 de K.

\section{Resultados e Discussão}

\section{Rendimento de massa seca e exportação de $\mathrm{P}$ e $\mathrm{K}$ pelas forrageiras}

$\mathrm{O}$ rendimento de massa seca no experimento com doses de $\mathrm{P}$ variou entre os cultivos, de 11,2 a $18,1 \mathrm{Mg} \mathrm{ha}^{-1}$ nos híbridos sorgo, e de 18,2 a 23,6 Mg ha $^{-1}$ nos híbridos de milho (Tabela 2 ). No experimento com doses de $\mathrm{K}$, os valores foram semelhantes, com menor rendimento no cultivo de sorgo em 2015. A baixa produção de massa seca provavelmente está relacionada à redução da disponibilidade de água no solo, que ocorreu durante a estiagem de 21 dias consecutivos no mês de março e 12 dias no mês de abril, respectivamente (Figura 1). Nas demais safras, com regime hídrico adequado, houve menor variação no rendimento de massa seca.

A produtividade de massa seca de milho e sorgo para silagem é dependente do híbrido, da época de semeadura e da disponibilidade hídrica e de nutrien- tes, que são fatores que podem variar na mesma safra ou em safras diferentes para o mesmo híbrido utilizado (Von Pinho et al., 2007; Księżak et al., 2012; Moraes et al., 2013). Estudos mostram produtividade de sorgo entre 21,6 e 23,1 $\mathrm{Mg} \mathrm{ha}^{-1}$ e de milho entre 17,6 e 21,1 $\mathrm{Mg} \mathrm{ha}^{-1}$ (Von Pinho et al., 2007; Oliveira et al., 2010; Rabêlo et al., 2013; Ueno et al., 2013; Santos et al., 2015), indicando que os híbridos utilizados no presente estudo apresentaram adequada produção de massa seca.

A quantidade de $\mathrm{P}$ exportada pela massa seca das forrageiras apresentou resposta à adubação fosfatada em duas safras de milho (Tabela 2). Em 2014/15 e 2015/16, o incremento foi até as doses de 91 e 139 $\mathrm{kg} \mathrm{ha}^{-1}$ de $\mathrm{P}_{2} \mathrm{O}_{5}$, respectivamente, indicando redução do estoque inicial do nutriente no solo. Na média de cada cultivo, a quantidade exportada foi entre 65,0 e $132,7 \mathrm{~kg} \mathrm{ha}^{-1}$ de $\mathrm{P}_{2} \mathrm{O}_{5}$, destacando a massa seca como o principal fator que contribuiu para a variabilidade da quantidade exportada, pois a concentração do nutriente, semelhante ao K, apresentou pouca variação entre os cultivos.

Oliveira et al. (2010) em um estudo com milho e sorgo para silagem no Centro-Sul Baiano encontraram exportação de 75,8 e $68,0 \mathrm{~kg} \mathrm{ha}^{-1}$ de $\mathrm{P}_{2} \mathrm{O}_{5}$, respectivamente, em solo com adequada disponibilidade de nutrientes. Os autores destacam que o P é o terceiro elemento exportado em maior quantidade pela silagem de milho, ressaltando a importância do seu manejo para atender a demanda das plantas em cultivos sucessivos de forrageiras destinadas à produção de silagem.

Com relação ao experimento com adubação potássica, não houve alteração na quantidade de $\mathrm{K}$ exportado das plantas de milho e sorgo em função das doses do nutriente (Tabela 2). Na média de cada cultivo, foram encontrados valores entre 164,9 e $327,7 \mathrm{Kg}$ 
ha $^{-1}$ de $\mathrm{K}_{2} \mathrm{O}$. Destaca-se que o potássio é o nutriente exportado em grande quantidade pelas plantas forrageiras, podendo ser o primeiro (Oliveira et al., 2010; Santos et al., 2015) ou o segundo (Von Pinho et al., 2009; Ueno et al., 2013) comparado ao N na ordem de exportação, com valores relatados pelos mesmos autores entre 170,4 e $357,6 \mathrm{Kg} \mathrm{ha}^{-1}$ de $\mathrm{K}_{2} \mathrm{O}$. A alta taxa de exportação do nutriente adverte a necessidade de trabalhar adequadamente a sua reposição para atender o suprimento às plantas e evitar a redução do estoque no solo.

A ausência de resposta à adubação potássica na produção de massa seca e na quantidade de K exportado pelas plantas forrageiras pode estar relacionada à elevada disponibilidade do nutriente no solo $(\mathrm{Pa}-$ vinato et al., 2008). Os níveis de nutrientes no solo indicaram, na implantação do experimento, teores de 309,5 e $179,5 \mathrm{mg} \mathrm{dm}^{-3}$ na camada de $0-10$ e $10-20$

Tabela 2. Equações de regressões da massa seca e da quantidade de nutriente exportado pelas culturas de milho e sorgo em função das doses de P e K aplicadas na semeadura das culturas.

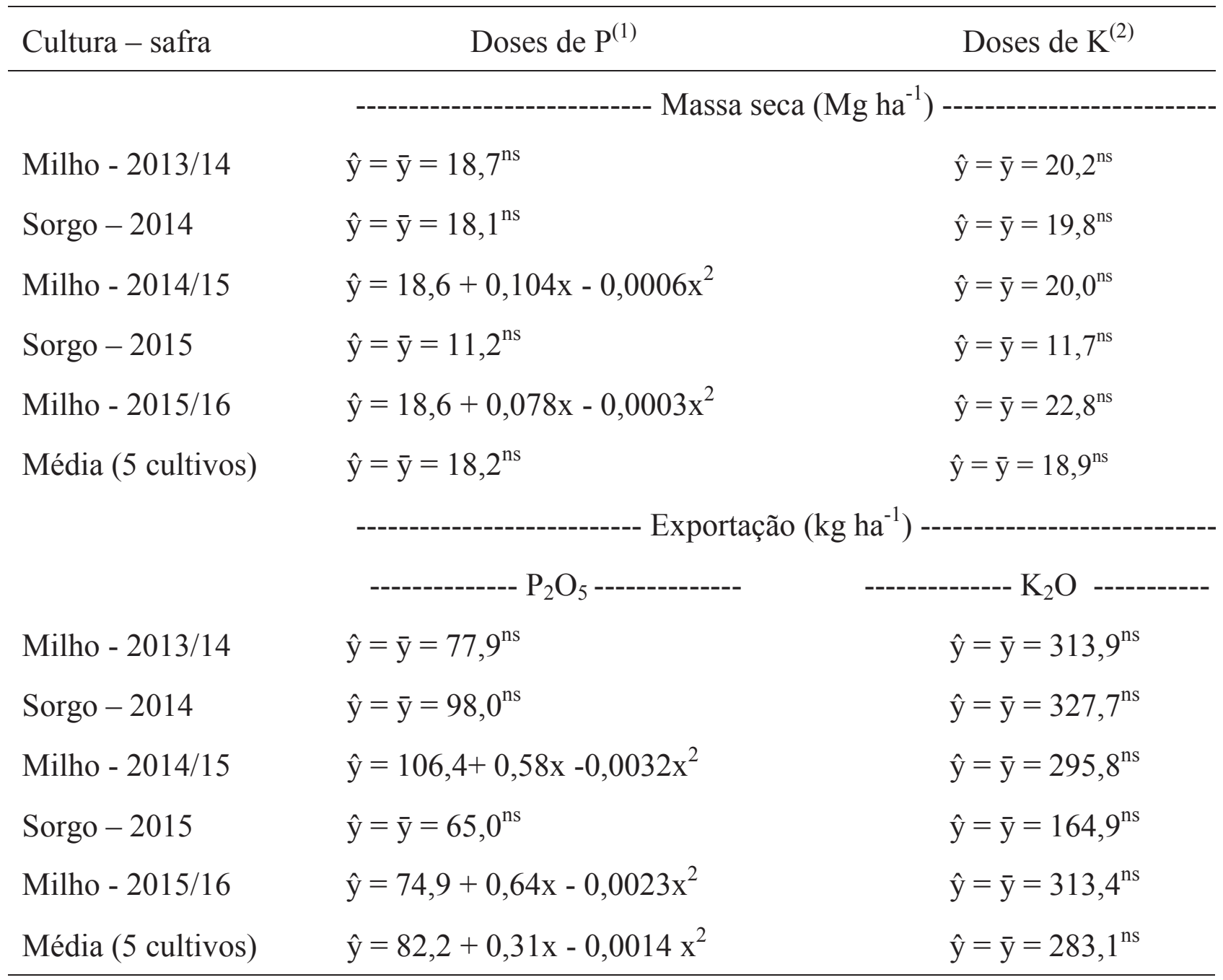

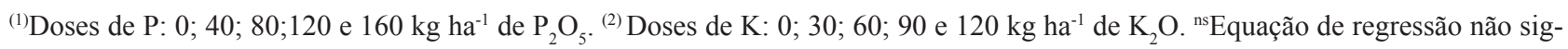
nificativa $(\mathrm{p} \leq 0,05)$. 
cm, respectivamente (Tabela 1). Estes valores são classificados, respectivamente, como "muito alto" e "alto" conforme a Comissão de Química e Fertilidade do Solo (Manual..., 2016) para solos com CTC potencial entre 7,6 e 15,0 $\mathrm{cmol}_{\mathrm{c}} \mathrm{dm}^{-3}$, provavelmente pelas adubações realizadas nos cultivos anteriores à implantação do experimento. Considerando o nível crítico de $90 \mathrm{mg} \mathrm{dm}^{-3}$ de $\mathrm{K}$ no solo, observam-se valores 3,4 vezes superiores na camada de $0-10 \mathrm{~cm}$ que é usada como referência para avaliar a disponibilidade do nutriente em áreas de plantio direto estabelecido.

\section{Balanço de $\mathbf{P}$ e $\mathrm{K}$ no cultivo sucessivo de milho e sorgo}

A quantidade de P necessária para contrabalançar as perdas por exportação no sistema de produção de milho e sorgo para silagem, calculada pela diferença entre a quantidade do nutriente fornecida via fertilizante e a exportada pela massa seca (dose de reposição), indicou valores médios negativos abaixo de $95,3 \mathrm{~kg} \mathrm{ha}^{-1}$ de $\mathrm{P}_{2} \mathrm{O}_{5}$ (Figura 2A). Valor condizente a este estudo foi encontrado por Ueno et al. (2013) com milho para produção de silagem, em solo com $1,1 \mathrm{mg} \mathrm{dm}^{-3}$ de $\mathrm{P}$ e fertilizado com $105 \mathrm{~kg} \mathrm{ha}^{-1}$ de $\mathrm{P}_{2} \mathrm{O}_{5}$ na semeadura da cultura, onde a dose de reposição estabelecida foi $96,5 \mathrm{~kg} \mathrm{ha}^{-1}$ de $\mathrm{P}_{2} \mathrm{O}_{5}$ com rendimento de $17,6 \mathrm{Mg} \mathrm{ha}^{-1}$ de massa seca.

Considerando a dose de reposição e a produção média de massa seca $\left(18,2 \mathrm{Mg} \mathrm{ha}^{-1}\right)$, foi necessário aplicar 5,2 $\mathrm{kg}$ de $\mathrm{P}_{2} \mathrm{O}_{5}$ para cada megagrama de massa seca produzida pelas forrageiras. Este valor está dentro dos intervalos quando se reúnem informações de diferentes estudos, com valores entre 1,8 e 7,6 kg de $\mathrm{P}_{2} \mathrm{O}_{5} \mathrm{Mg}^{-1}$ no sorgo, e de 3,4 a 6,1 kg de $\mathrm{P}_{2} \mathrm{O}_{5} \mathrm{Mg}^{-1}$ no milho (Von Pinho et al., 2009; Oliveira et al., 2010; Ueno et al., 2013; Santos et al., 2015).
O uso da média da concentração de $\mathrm{P}$ pode ser uma alternativa quando se trabalha com cultivos sucessivos destas duas forrageiras, pois as diferenças tendem a ser maiores entre os híbridos da mesma cultura (Tabela 2). No caso do milho, Santos et al. (2015) relatam em uma revisão que é possível trabalhar com valor de $6,9 \mathrm{~kg}$ de $\mathrm{P}_{2} \mathrm{O}_{5} \mathrm{Mg}^{-1}$ de massa seca para diferentes híbridos e condições edafoclimáticas. Isto indica que não há necessidade de trabalhar com dados individuais de concentração de $\mathrm{P}$ para as culturas de sorgo e milho.

$\mathrm{O}$ balanço de K no sistema de produção de milho e sorgo para silagem mostrou valores negativos em todas as doses do nutriente aplicadas no solo (Figura 2B). A equação de regressão do balanço de K no sistema de produção das forrageiras indica a necessidade de aplicar $297,3 \mathrm{~kg} \mathrm{ha}^{-1}$ de $\mathrm{K}_{2} \mathrm{O}$ por cultivo para contrabalançar as perdas por exportação (dose de reposição).

Observa-se que a dose de reposição representou 2,5 vezes a adubação máxima utilizada no presente estudo $\left(120,0 \mathrm{~kg} \mathrm{ha}^{-1}\right.$ de $\left.\mathrm{K}_{2} \mathrm{O}\right)$. O uso desta dose durante a condução do experimento foi com base na recomendação da $10^{a}$ edição da Comissão de Química e Fertilidade do Solo (Manual..., 2004) para uma expectativa de $12 \mathrm{Mg} \mathrm{ha}^{-1}$ de produção de massa seca em solos com teores de $\mathrm{K}$ acima do adequado (muito alto), com indicação de $\leq 130,0 \mathrm{~kg} \mathrm{ha}^{-1}$ de $\mathrm{K}_{2} \mathrm{O}$. A $11^{\text {a }}$ edição da Comissão de Química e Fertilidade do Solo (Manual..., 2016) considera, para as mesmas condições de solo, doses $\leq 220 \mathrm{~kg} \mathrm{ha}^{-1}$ de $\mathrm{K}_{2} \mathrm{O}$, se aproximando mais dos valores obtidos de exportação do nutriente no presente estudo.

Com base na produção média de $18,9 \mathrm{Mg} \mathrm{ha}^{-1}$ de massa seca nos cinco cultivos e na dose de reposição de $\mathrm{K}\left(297,3 \mathrm{~kg} \mathrm{ha}^{-1}\right.$ de $\left.\mathrm{K}_{2} \mathrm{O}\right)$, indica-se a necessidade de aplicar $15,7 \mathrm{~kg}$ de $\mathrm{K}_{2} \mathrm{O} \mathrm{Mg}^{-1}$ de massa seca. 
Informações de diferentes estudos com as mesmas culturas mostram valores entre 9,8 e 15,1 e entre 9,7 e $11,8 \mathrm{~kg}$ de $\mathrm{K}_{2} \mathrm{O} \mathrm{Mg}^{-1}$ de matéria seca para o sorgo e o milho, respectivamente (Oliveira et al., 2010; Ueno et al., 2013; Galvão et al., 2015). Em uma revisão de vários trabalhos, Santos et al. (2015) relatam valor médio de $15,0 \mathrm{~kg}$ de $\mathrm{K}_{2} \mathrm{O} \mathrm{Mg}^{-1}$ de massa seca para a cultura do sorgo, e Ueno et al. (2011) de 10,4 kg de $\mathrm{K}_{2} \mathrm{O} \mathrm{Mg}^{-1}$ de massa seca para o milho. Estes dados indicam uma tendência de maior concentração de $\mathrm{K}$ na massa seca da cultura do sorgo, o que não foi possível de se observar no presente estudo.

Destaca-se que a recomendação de adubação da Comissão de Química e Fertilidade do Solo (Ma-
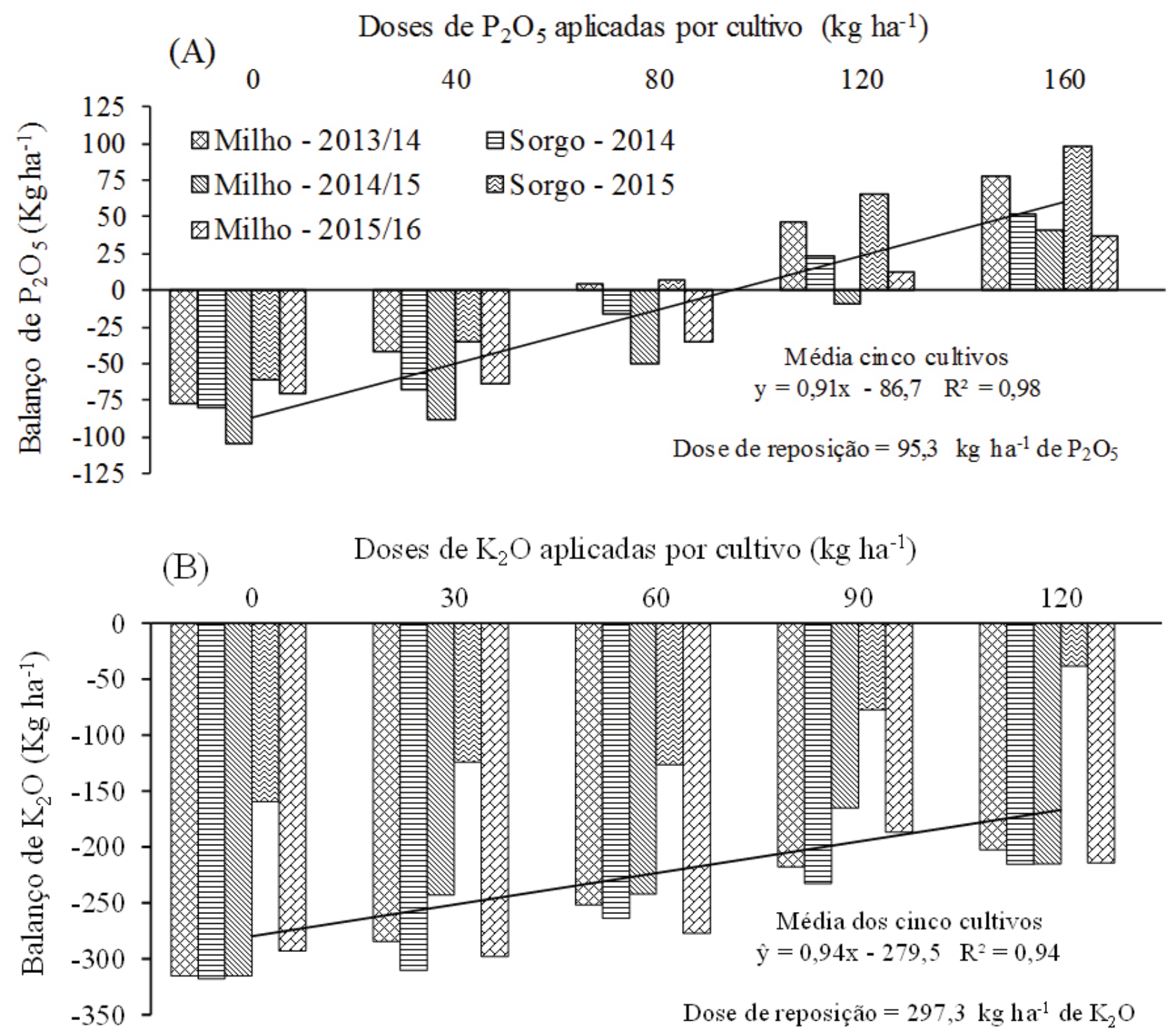

Figura 2. Balanço de $\mathrm{P}$ (A) e K (B) no sistema de produção de silagem de milho e sorgo para silagem durante cinco cultivos sucessivos em função das doses dos nutrientes aplicadas em cada cultivo. 
nual..., 2016) para os cultivos de milho e sorgo para silagem em solos com teor "muito alto" de P e K, igual ao presente estudo, não especifica as quantidades dos nutrientes para adicionar por unidade de massa seca produzida para contrabalançar somente as perdas por exportação (dose de reposição). A substituição da dose de manutenção para reposição na recomendação da adubação fosfatada e potássica nas culturas de milho e sorgo destinadas a silagem é uma alternativa que pode ser utilizada em áreas com teores "muito alto" do nutriente no solo, semelhante à utilizada pela Comissão de Química e Fertilidade do Solo (Manual..., 2016) nas culturas de grãos. Kaminski et al. (2010) destacam que os programas de adubação devem prever o estabelecimento de um nível de suficiência, a partir do qual a dose recomendada deve acompanhar as necessidades das culturas, que coincidem com a quantidade exportada pelas plantas.

\section{Teores de P e K no solo após os cinco cultivos sucessivos de milho e sorgo}

$\mathrm{O}$ teor inicial de $\mathrm{P}$ disponível no solo reduziu com a ausência da adubação fosfatada após cinco cultivos sucessivos de milho e sorgo, de 13,4 para 4,7 e de 9,3 para 4,1 $\mathrm{mg} \mathrm{dm}^{-3}$ nas camadas de $0-10$ e 0-20 cm, respectivamente (Figura 3A e B). Nestas mesmas camadas, foi necessário aplicar, respectivamente, 51,2 e 57,8 $\mathrm{kg} \mathrm{ha}^{-1}$ de $\mathrm{P}_{2} \mathrm{O}_{5}$ para a manutenção dos teores iniciais. Este resultado explica a resposta à adubação fosfatada na produção de massa seca nos dois últimos cultivos de milho.

Com o uso da dose de reposição de $\mathrm{P}(95,3 \mathrm{~kg}$ ha $^{-1}$ de $\mathrm{P}_{2} \mathrm{O}_{5}$ ) estimou-se em $20,9 \mathrm{mg} \mathrm{dm}^{-3}$ na camada de $0-10 \mathrm{~cm}$ (Figura 3A) e em $12,7 \mathrm{mg} \mathrm{dm}^{-3}$ na camada de 0-20 cm (Figura 3B). Observa-se que estes teores foram superiores à faixa adequada de $\mathrm{P}$ nas duas camadas de solo avaliadas, indicando a necessidade de mais cultivos de milho e sorgo para reduzir os teores do nutriente de "muito alto" para "alto" (faixa adequada) com o uso da dose de reposição.

A estimativa da dose de $\mathrm{P}$, aplicada a lanço, para manter os teores do nutriente no limite superior da faixa adequada no solo $\left(12,0 \mathrm{mg} \mathrm{dm}^{-3}\right)$ foi de 42,9 $\mathrm{kg} \mathrm{ha}^{-1}$ de $\mathrm{P}_{2} \mathrm{O}_{5}$ na camada de 0-10 cm (Figura 3B) e de $87,8 \mathrm{~kg} \mathrm{ha}^{-1}$ de $\mathrm{P}_{2} \mathrm{O}_{5}$ na camada de 0-20 cm (Figura 3B). Na camada de 0-20 cm, a dose de P estimada para manter o teor de $\mathrm{P}$ no limite superior da faixa adequada foi somente 7,5 $\mathrm{kg} \mathrm{ha}^{-1}$ de $\mathrm{P}_{2} \mathrm{O}_{5}$ menor do que à dose de reposição. Estes dados mostram que a dose de reposição de $\mathrm{P}$ apresenta maior relação com a disponibilidade do nutriente no solo quando avaliada a camada de $0-20 \mathrm{~cm}$.

Comparando o teor inicial de $\mathrm{P}$ no solo com o teor final com o uso da dose de equilíbrio, observa-se aumento de 7,5 $\mathrm{mg} \mathrm{dm}^{-3}$ de $P$ na camada de $0-10 \mathrm{~cm}$ e diminuição de $0,8 \mathrm{mg} \mathrm{dm}^{-3}$ na camada de $10-20 \mathrm{~cm}$ (Figura 3). O aumento de $\mathrm{P}$ na camada superficial está relacionado à aplicação do fertilizante a lanço na superfície do solo. O P é um nutriente que tende a se acumular na camada superficial do solo por causa da alta energia de adsorção do ânion fosfato às cargas positivas dos coloides, principalmente com aplicação superficial da adubação em áreas de plantio direto. Esta acumulação é intensificada em solos argilosos e com alta concentração de óxidos de ferro (Motta et al., 2002).

O menor teor de P no solo na camada de 10-20 $\mathrm{cm}$ após cinco cultivos de milho e sorgo em comparação ao teor inicial na implantação do experimento indica que a extração de $\mathrm{P}$ pelas plantas não se limitou somente à camada superficial do solo. A saturação por Al trocável e a densidade do solo abaixo do limite crítico de crescimento do sistema radicular, provavelmente, foram os fatores que contribuíram para o cres- 

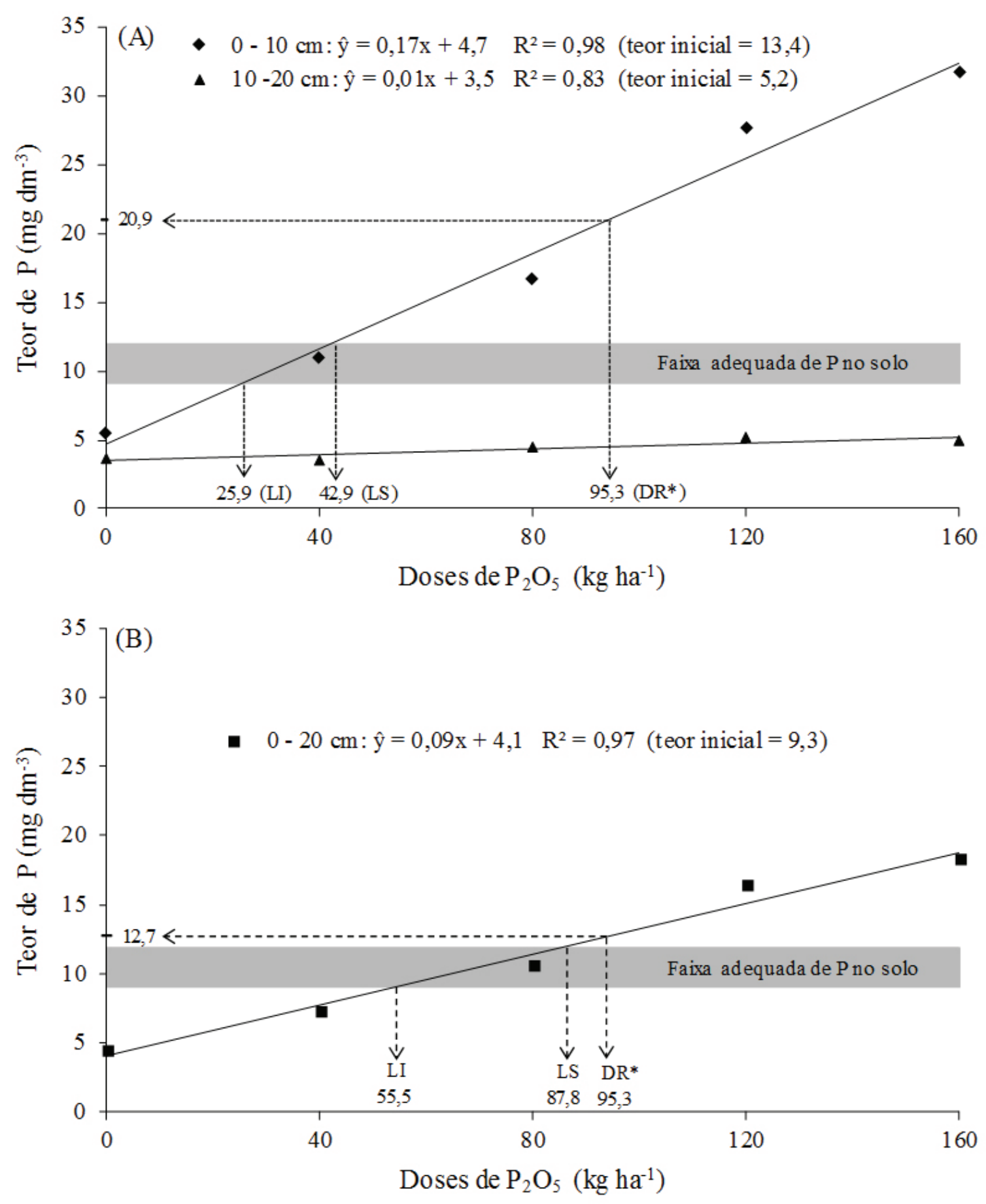

Figura 3. Teores de $\mathrm{P}$ disponíveis na camada de 0-10 e 10-20 cm (A) e de 0-20 cm (B) após cinco cultivos sucessivos de milho e sorgo para silagem em função das doses do nutriente aplicadas em cada cultivo e as respectivas doses para manter os teores no limite inferior (LI) e no limite superior (LS) da faixa adequada. (* teor de P no solo com a dose de reposição - DR) 
cimento radicular e a extração de $\mathrm{P}$ em profundidade no perfil do solo. A saturação por Al somente ultrapassou o limite crítico (10\%) abaixo de $100 \mathrm{~cm}$ de profundidade, e a densidade não ultrapassou o limite crítico de 1,30 $\mathrm{Mg} \mathrm{m}^{-3}$ (Reynolds et al., 2002; Sá et al., 2016) em todo o perfil do solo avaliado $(0-180 \mathrm{~cm})$.

$\mathrm{O}$ aumento de $\mathrm{P}$ em profundidade somente ocorre após a saturação dos sítios de adsorção com altas e frequentes doses de adubação fosfatada, que provavelmente aconteceu em pequena intensidade no presente estudo, indicando pouco deslocamento do nutriente em profundidade mesmo com doses de $\mathrm{P}$ acima da quantidade exportada. O uso de sulcadores na distribuição do fertilizante na linha de semeadura das forrageiras é uma prática que pode contribuir para aumentar o teor de $\mathrm{P}$ em profundidade e reduzir o gradiente do nutriente no perfil do solo, mesmo em áreas que necessitam somente a adubação de reposição.

A exportação de $\mathrm{K}$ pela fitomassa das forrageiras, durante cinco cultivos sucessivos de milho e sorgo sem adubação potássica, reduziu os teores do nutriente no solo de 309,5 para 96,7 e de 179,5 para $55,0 \mathrm{mg} \mathrm{dm}{ }^{-3}$ na camada de 0-10 e 10-20 cm, respectivamente (Figura 4A). Em um sistema de produção de forrageiras para silagem durante seis anos com as culturas de milho ou sorgo no verão, e azevém ou aveia-preta no inverno (total de 12 cultivos), Silva et al. (2010) encontraram redução no teor inicial de K na camada de $0-10 \mathrm{~cm}$ de 235 para $66 \mathrm{mg} \mathrm{dm}^{-3}$ no final do sexto ano com uso de $40 \mathrm{~kg} \mathrm{ha}^{-1}$ de $\mathrm{K}_{2} \mathrm{O}$ por cultivo.

Em outro estudo durante 16 anos, Kaminski et al. (2010) observaram que a adição de doses de K em quantidades menores às exportadas pelas plantas causam redução de $\mathrm{K}$ disponível no solo (extraído por Mehlich-1) e também das formas não trocáveis. Os autores encontraram redução de 50,0 para $27,0 \mathrm{mg}$ $\mathrm{dm}^{-3}$ e destacam que a redução do teor do nutriente no solo é por causa da absorção pelas plantas, já que não há quantidades consideráveis de $\mathrm{K}$ adsorvido por quimiossorção, como ocorre, por exemplo, com o P em solos com alto teor de óxidos de ferro.

Apesar da redução do teor de K no solo, a ausência de adubação potássica durante cinco cultivos sucessivos de milho e sorgo para silagem manteve os teores do $\mathrm{K}$ no solo na camada de $0-10 \mathrm{~cm}$ dentro da faixa adequada (91 a $180 \mathrm{mg} \mathrm{dm}^{-3}$ ) (Figura 4A). O valor próximo ao limite inferior desta classe indica que para os próximos cultivos há possibilidade de resposta à adubação potássica. $\mathrm{O}$ limite superior à faixa adequada de nutrientes $\left(180 \mathrm{mg} \mathrm{dm}^{-3}\right)$ foi obtido com aplicação de 49,0 $\mathrm{kg} \mathrm{ha}^{-1}$ de $\mathrm{K}_{2} \mathrm{O}$, porém esta dose não garante a manutenção do mesmo teor de $\mathrm{K}$ no solo nos próximos cultivos por causa da alta exportação do nutriente.

O uso da adubação potássica contribuiu para aumentar o teor do nutriente no solo nas camadas de 0-10 e 10-20 cm, mas não suficiente para manter os teores originais do nutriente no solo, mesmo com a dose máxima do fertilizante aplicada em cada cultivo (120 kg ha ${ }^{-1}$ de $\left.\mathrm{K}_{2} \mathrm{O}\right)$, principalmente na camada de 10-20 cm (Figura 4A). Com a dose máxima de adubação potássica os teores de $\mathrm{K}$ foram de 300,7 e $210,3 \mathrm{mg} \mathrm{dm}^{-3}$ na camada de $0-10$ e $10-20 \mathrm{~cm}$, representando uma redução de 2,8 e $32,6 \%$, respectivamente, em comparação com os teores originais de $\mathrm{K}$ no solo. Estes dados mostram que a avaliação da disponibilidade de $\mathrm{K}$ somente na camada de 0-10 $\mathrm{cm}$ em áreas de plantio direto com aplicação da adubação a lanço deve ser usada com critério para avaliar a necessidade de reposição de K para as plantas, pois a dose de adubação pode condicionar redução do nutriente abaixo do nível crítico em camadas sub- 

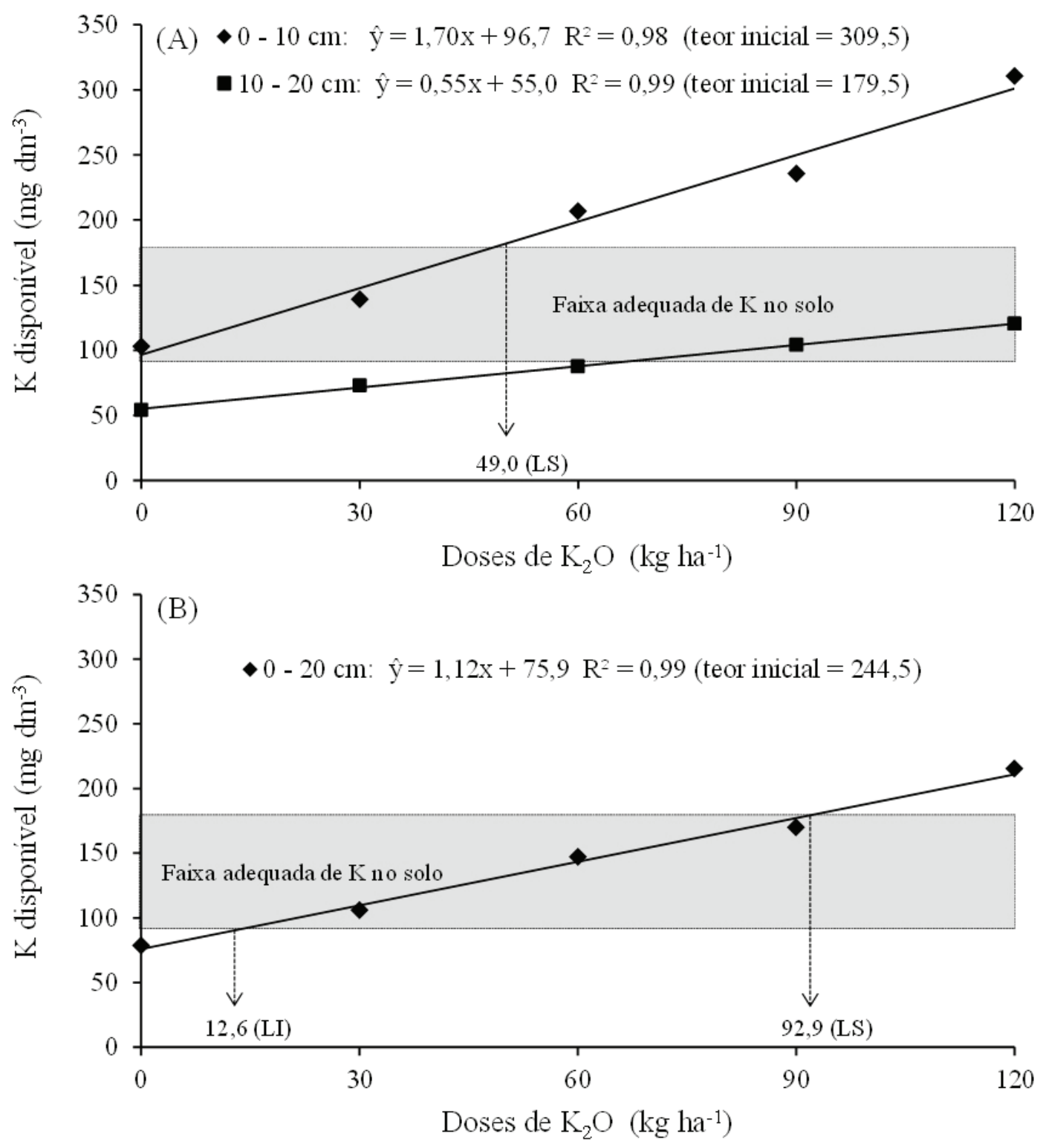

Figura 4. Teores de K disponível na camada de 0-10 e 10-20 cm (A) e de 0-20 cm (B) após cinco cultivos sucessivos de milho e sorgo para silagem em função das doses do nutriente aplicadas em cada cultivo e as respectivas doses para manter os teores no limite inferior (LI) e no limite superior (LS) da faixa adequada. 
superficiais e comprometer o adequado suprimento pelas plantas.

A expectativa de redução do teor de K no solo após cinco cultivos das forrageiras sem uso de adubação deveria ser maior quando computada a quantidade total de $\mathrm{K}$ exportada nos cinco cultivos (1.145,7 $\mathrm{kg} \mathrm{ha}^{-1}$ de $\mathrm{K}_{2} \mathrm{O}$ ) (Tabela 2), pois este valor equivale à redução de $572,8 \mathrm{mg} \mathrm{dm}^{-3}$ de $\mathrm{K}$ no solo, considerando a camada de $0-20 \mathrm{~cm}$. Observa-se pela equação de regressão da Figura 4B que a dose de $\mathrm{K}$ para manter os teores originais na camada de $0-20 \mathrm{~cm}$ foi de 150,5 $\mathrm{kg} \mathrm{ha}^{-1}$ de $\mathrm{K}_{2} \mathrm{O}$ por cultivo, valor significativamente menor em comparação à quantidade exportada pela fitomassa das forrageiras.

A distribuição em profundidade dos teores originais de $\mathrm{K}$, com valores acima do teor crítico até a camada de 20-40 cm (Tabela 1), provavelmente contribuiu com parte do suprimento de $\mathrm{K}$ às plantas de milho e sorgo, resultando em menor diminuição dos teores de $\mathrm{K}$ na camada superficial do solo (Kaminski et al., 2010). A disponibilização de $\mathrm{K}$ na forma não trocável também pode ter contribuído para o suprimento de $\mathrm{K}$ às plantas (Kaminski et al., 2007). Estas duas condições possivelmente foram responsáveis pela menor necessidade de $\mathrm{K}$ via adubação em comparação com a quantidade exportada, em consonância com baixa redução na camada superficial do solo, justificando novamente a ausência de resposta na produção de massa seca das forrageiras durante cinco cultivos sucessivos em área sem o uso de adubação potássica.

\section{Agradecimentos}

Ao Fundo de Incentivo à Pesquisa (FIPE) da Universidade Federal de Santa Maria pela concessão de bolsa de estudo.

\section{Conclusões}

O uso da dose de reposição durante cinco cultivos sucessivos de milho e sorgo para silagem mantém os teores disponíveis de $\mathrm{P}$ próximo e o $\mathrm{K}$ acima dos teores originais na camada de $0-20 \mathrm{~cm}$.

As doses de reposição de nutrientes em áreas de cultivos sucessivos de milho e sorgo para silagem é estimada em $5,2 \mathrm{~kg}$ de $\mathrm{P}_{2} \mathrm{O}_{5}$ e de $15,7 \mathrm{~kg}$ de $\mathrm{K}_{2} \mathrm{O}$ por megagrama de matéria seca produzida.

\section{Referências}

ALVARES, C. A.; STAPE, J. L.; SENTELHAS, P. C.; MORAES GONÇALVES, J. L.; SPAROVEK, G. Köppen's climate classification map for Brazil. Meteorologische Zeitschrift, v. 22, n. 6, p. 711-728, 2013. DOI: $10.1127 / 0941-2948 / 2013 / 0507$.

DONAGEMA, G. K.; CAMPOS, D. V. B. de; CALDERANO, S. B.; TEIXEIRA, W. G.; VIANA, J. H. M. (Org.). Manual de métodos de análise de solo. 2. ed. rev. Rio de Janeiro: Embrapa Solos, 2011. 230 p. (Embrapa Solos. Documentos, 132).

GALVÃO, J. R.; FERNANDES, A. R.; SIVA, V. A.; PINHEIRO, D. P.; MELO, N. C. Adubação potássica em híbridos de sorgo forrageiro cultivados em sistemas de manejo do solo na Amazônia Oriental. Revista Caatinga, Mossoró, v. 28, n. 4, p. 70-79, 2015.

DOI: $10.1590 / 1983-21252015 \mathrm{v} 28 \mathrm{n} 408 \mathrm{rc}$.

KAMINSKI, J.; BRUNETTO, G.; MOTERLE, D. F.; RHEINHEIMER, D. S. Depleção de formas de potássio do solo afetada por cultivos sucessivos. Revista Brasileira de Ciência do Solo, Viçosa, MG, v. 31, n. 5, p. 1003-1010, 2007. DOI: $10.1590 / \mathrm{S} 0100-06832007000500017$.

KAMINSKI, J.; MOTERLE, D. F.; RHEINHEIMER, D. S.; GATIBONI, L. C.; BRUNETTO, G. Potassium availability in a hapludalf soil under long term fertilization. Revista Brasileira de Ciência do Solo, Viçosa, MG, v. 34, p. 783791, 2010. DOI: 10.1590/S0100-06832010000300020. 
KSIĘŻAK, J.; MATYKA, M.; BOJARSZCZUK. J.; KACPRZAK, A. Evaluation of productivity of maize and sorghum to be used for energy purposes as influenced by nitrogen fertilization. Zemdirbyste-Agriculture, v. 99, n. 4, p. 363-370, 2012.

MANUAL de calagem e adubação para os Estados do Rio Grande do Sul e de Santa Catarina. 11. ed. Porto Alegre: Sociedade Brasileira de Ciência do Solo, Núcleo Regional Sul, Comissão de Química e Fertilidade do Solo, 2016.376 p.

MANUAL de adubação e de calagem para os Estados do Rio Grande do Sul e Santa Catarina. 10 ed. Porto Alegre: Sociedade Brasileira de Ciência do Solo, Núcleo Regional Sul-Comissão deQuímica e Fertilidade do Solo, 2004.400 p.

MIYAZAWA, M.; PAVAN, M. A.; CARMO, C. A. F. S.; MELO, W. J. Análise química de tecido vegetal. In: SILVA, F. C. (Ed.). Manual de análises químicas de solos, plantas e fertilizantes. 2. ed. Brasília, DF: Embrapa Informação Tecnológica, 2009. p. 191-233.

MORAES, S. D.; JOBIM, C. C.; SILVA, M. S.; MARQUARDT, F. I. Produção e composição química de híbridos de sorgo e de milho para silagem. Revista Brasileira de Saúde e Produção Animal, Salvador, v. 14, n. 4, p. 624-634, 2013.

DOI: 10.1590/S1519-99402013000400002.

MOTTA, P. E. F.; CURI, N.; SIQUEIRA, J. O.; VAN RAIJ, B.; FURTINI NETO, A. E.; LIMA, J. M. Adsorção e formas de fósforo em Latossolos: influência da mineralogia e histórico de uso. Revista Brasileira de Ciência do Solo, Viçosa, MG, v. 26, n. 2, p. 349-359, 2002.

DOI: 10.1590/S0100-06832002000200008.

OLIVEIRA, L. B.; PIRES, A. J. V.; VIANA, A, E. S.; MATSUMOTO, S. N.; PINTO, G. G. Produtividade, composição química e características agronômicas de diferentes forrageiras. Revista Brasileira de Zootecnia, v. 39, n. 12, p. 2604-2610, 2010.

DOI: $10.1590 / \mathrm{S} 1516-35982010001200007$.

PAVINATO, P. S.; CERETTA, C. A.; GIROTTO, E.; MOREIRA, I. C. L. Nitrogênio e potássio em milho irrigado: análise técnica e econômica da fertilização. Ciência Rural, Santa Maria, v. 38, n. 2, p. 358-364, 2008. DOI: $10.1590 /$ S0103-84782008000200010.

RABÊLO, F. H. S.; RABÊLO, F. H. S.; REZENDE, A.V.; RABELO, C. H. S.; AMORIM, F. A. Características agronômicas e bromatológicas do milho submetido a adubações com potássio na produtividade de silagem. Revista Ciência Agronômica, Fortaleza, v. 44, n. 3, p. 635-643, 2013.

DOI: 10.1590/S1806-66902013000300028.

REYNOLDS, W. D.; BOWMAN, B. T.; DRURY, C.; TAN, C.; LU, X. Indicators of good soil physical quality: density and storage parameters. Geoderma, Amsterdam, v. 110, n. 1/2, p. 131-146, 2002.

DOI: $10.1016 / \mathrm{S} 0016-7061(02) 00228-8$.

SÁ, M. A. C.; SANTOS JÚNIOR, J. D. G.; FRANZ, C. A. B.; REIN, T. A. Qualidade física do solo e produtividade da cana-de-açúcar com uso da escarificação entre linhas de plantio. Pesquisa Agropecuária Brasileira, Brasília, DF, v. 51, n. 9, p. 1610-1622, 2016.

DOI: $10.1590 / \mathrm{S} 0100-204 X 2016000900061$.

SANTOS, F. C. S.; ALBUQUERQUE FILHO, M. R.; RESENDE, A. V.; OLIVEIRA, A. C.; OLIVEIRA, M. S.; GOMES, T. C. Adubação nitrogenada e potássica na nutrição e na extração de macronutrientes pelo sorgo biomassa. Revista Brasileira de Milho e Sorgo, v. 14, n. 1, p. 10-22, 2015.

DOI: 10.18512/1980-6477/rbms.v14n1p10-22.

SANTOS, H. G. dos; JACOMINE, P. K. T.; ANJOS, L. H. C. dos; OLIVEIRA, V. A. de; LUMBRERAS, J. F.; COELHO, M. R.; ALMEIDA, J. A. de; CUNHA, T. J. F.; OLIVEIRA, J. B. de. Sistema brasileiro de classificação de solos. 4. ed. Brasília, DF: Embrapa, 2014. 376 p.

SCHLINDWEIN, J. A.; GIANELLO, C. Calibração de métodos de determinação de fósforo em solos cultivados sob sistema plantio direto. Revista Brasileira de Ciência do Solo, Viçosa, MG, v. 32, n. 5, p. 2037-2049, 2008.

DOI: 10.1590/S0100-06832008000500025. 
SILVA, F. C.; ABREU, M. F.; PÉREZ, D. V. Métodos de análises químicas para avaliação da fertilidade do solo. In: SILVA, F. C. (Ed.). Manual de análises químicas de solos, plantas e fertilizantes. 2. ed. Brasília, DF: Embrapa Informações Tecnológica, 2009. p. 107-189.

SilVA, J. C. P. M.; PAUleTti, V.; VElOSO, C. M.; FAVARETTO, N.; BARCELLOS, M.; OLIVEIRA, A. S.; COSTA E SILVA, L. F. Esterco de gado leiteiro associado à adubação mineral e sua influência na fertilidade de um Latossolo sob plantio direto. Revista Brasileira de Ciência do Solo, Viçosa, MG, v. 34, n. 2, p. 453-463, 2010 .

DOI: $10.1590 / \mathrm{S} 0100-06832010000200019$.

SKONIESKI, F. R.; NORNBERG, J. L.; AZEVEDO, E. B. de; DAVID, D. B.; KESSLER, J. D.; MENEGAZ, A. L. Produção, caracterização nutricional e fermentativa de silagens de sorgo forrageiro e sorgo duplo propósito. Acta Scientiarum. Animal Sciences, Maringá, v. 32, n. 1, p. 27-32, 2010.

DOI: $10.4025 /$ actascianimsci.v32i1.7200.
UENO, R. K.; NEUMANN, M.; MARAFON, F.; BASI, S.; ROSÁRIO, J. G. Dinâmica dos nutrientes do solo em áreas destinadas à produção de milho para forragem. Pesquisa Aplicada \& Agrotecnologia, v. 4, n. 1, p. 182-193, 2011.

UENO, R. K.; NEUMANN, M.; MARAFON, F.; REINEHR, L. L.; POCZYNEK, M.; MICHALOVICZ, L. Exportação de macronutrientes do solo em área cultivada com milho para alimentação de bovinos confinados. Semina. Ciências Agrárias, Londrina, v. 34, n. 6, p. 30013018, 2013. DOI: 10.5433/1679-0359.2013v34n6p3001.

VON PINHO, R. G.; VASCONCELOS, R. C.; BORGES, I. D.; RESENDE, A. V. Produtividade e qualidade da silagem de milho e sorgo em função da época de semeadura. Bragantia, Campinas, v. 66, n. 2, p. 235-245, 2007.

DOI: $10.1590 / \mathrm{S} 0006-87052007000200007$.

VON PINHO, R. G.; RIVERA, A. A. C.; BRITO, A. H.; LIMA, T. G. Avaliação agronômica do cultivo de milho em diferentes níveis de investimento. Ciência e Agrotecnologia, Lavras, v. 33, n. 1, p. 39-46, 2009. DOI: $10.1590 / \mathrm{S} 1413-70542009000100005$. 